\title{
EDUCAÇÃO FINANCEIRA: UM RELATO DE EXPERIÊNCIA NOS ANOS INICIAIS DO ENSINO FUNDAMENTAL
}

\author{
DIAS, F.1; KLAMT, S.C. ${ }^{2}$
}

PALAVRAS-CHAVE: Educação financeira. Crianças. Escola. Dinheiro.

\begin{abstract}
RESUMO
A situação atual da economia tornou como algo necessário o mínimo de domínio e conhecimento sobre planejamento financeiro. Contudo, a população, em sua grande maioria, não consegue administrar suas finanças, reflexo da falta de orientação quando mais jovens. Percebe-se, nas crianças, a chance de formar indivíduos responsáveis, comprometidos, que consumam com consciência e que tenham uma boa relação com o dinheiro. Com o objetivo de melhorar a percepção que as crianças têm sobre o dinheiro, este projeto, denominado " $A$ Importância da Educação Financeira Infantil", visou esclarecer a importância da educação financeira para os pequenos cidadãos, buscando formas de trabalhar este tema de maneira acessível aos alunos dos anos iniciais do ensino fundamental. A metodologia do projeto constou com algumas etapas para seu desenvolvimento. A primeira, refere-se à aplicação de questionários com professores e alunos. Após, iniciou-se a contação de histórias da coleção "O Menino do Dinheiro", atividade essa que foi desenvolvida antes do isolamento social em função do COVID-19. Através destes livros, buscou-se abordar de forma lúdica algumas situações que envolvam dinheiro direcionadas ao público infantil. Depois, foi confeccionado um cartaz, onde os alunos descreveram o que haviam aprendido durante a realização deste projeto. Para eles, através das conversas realizadas foi possível aprender: a economizar o dinheiro; utilizar o cofrinho, entre outros. Dessa forma, conclui-se que os objetivos do projeto foram alcançados. Foi possível sensibilizar os alunos da importância de ter uma relação saudável com o dinheiro. Além disso, a educação financeira mostrou-se ser um tema importantíssimo para trabalhar nas escolas.
\end{abstract}

\section{THE IMPORTANCE OF EARLY CHILDHOOD FINANCIAL EDUCATION}

KEYWORDS: Financial education. Children. School. Money.

\begin{abstract}
The current situasion of the economy has become like a necessary minimum knowledge and knowledge of dealing wuth Money. However, the population, for the most part, cannot manage their finances, a reflection of the lack of guidance when younger. It is then noticed, in children, the chance to form responsible, committes, who consume conscientiously and have a good relationship with Money. Aiming to improve the perception that childrenn have about Money, this project aims to clarify the importance of financial education for small citizens, seeking ways to work on this issue in na accessible way to children. In terms of methodology, the project had some stages for its development. The first refers to the application of questionnaires with teachers and students. Afterwards, the storytelling of the "The Money Boy" collection began, na activity that was developed before the social isolation due to Covid-19. Through these books, we made, where students describe what they learned during this project. For them, through the conversations held, it was possible to learn: how to save Money; use the piggy bank, among others. Thus, it is concluded that the project objectives were achieved. It was possible to make students aware of the importance of a healthy relationshio with Money. In addition, financial education is revealed to be a very importante topic to work on in schools.
\end{abstract}




\section{INTRODUÇÃO}

Esse assunto é de suma relevância, pois as crianças que frequentam os anos iniciais do ensino fundamental, mesmo que com pouca idade, sofrem influência da mídia, seja ela através de comerciais de televisão, desenhos ou vídeos que assistem. Esta influência pode ocasionar adultos extremamente consumistas. É necessário planejamento familiar, pais que não tiveram nenhuma orientação de como lidar com o dinheiro, não terão a preocupação de orientar seus filhos, criando assim, consumidores desenfreados, que não conhecem a origem do dinheiro, tão pouco sabem administrá-lo.

0 problema expressa-se pelo fato de que o dinheiro tornou-se indispensável para a sobrevivência humana. É na infância que os indivíduos formam seu caráter, sendo assim imprescindível que criem bons hábitos financeiros, a fim de que na vida adulta tornem-se seres responsáveis e comprometidos, diminuindo os casos de endividamento que hoje assolam o Brasil.

O projeto "A Importância da Educação Financeira Infantil" busca mostrar a importância da educação financeira para o público infantil. Trabalhando este tema de maneira acessível e envolvendo situações de seu dia a dia, tem se como objetivo despertar nas crianças curiosidades sobre o dinheiro e conscientizá-las sobre a importância de economizar. Para isso, foi utilizada a contação de histórias da coleção "O Menino do Dinheiro" como principal etapa da metodologia. Além disso, também foram realizados questionários e confecção de cartazes. Este trabalho foi desenvolvido na Escola Municipal de Ensino Fundamental José de Anchieta, de Passo do Sobrado, com turmas de $4^{\circ}$ e $5^{\circ}$ ano.

\section{FUNDAMENTAÇÃO TEÓRICA}

\subsection{Saiba o que é Educação Financeira}

Desde os primeiros momentos de contato com o mundo a educação faz parte da vida dos seres humanos, pois através dela aprende-se a conviver e agir com pessoas e situações. 0 dinheiro também está presente desde os primeiros momentos de vida, sendo essencial que os indivíduos aprendam a conviver com ele de forma equilibrada, surgindo assim o termo educação financeira.

Segundo a Organização para Cooperação e Desenvolvimento Econômico (OCDE) de 2005, educação financeira é:

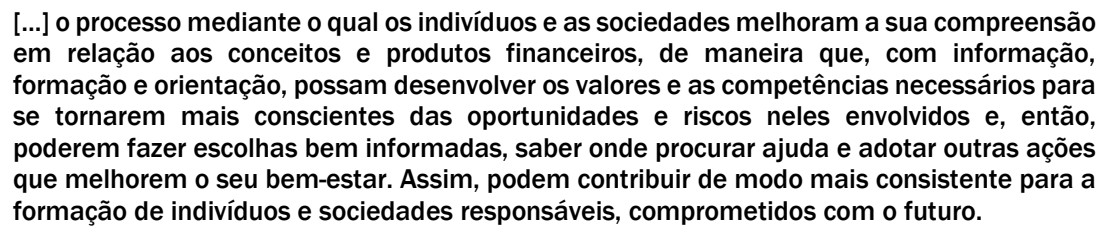

\subsection{A Educação Financeira no Brasil}

O Brasil ainda engatinha no que diz respeito a educação financeira. As pessoas vivenciam situações de compra e venda em seu dia a dia, porém em sua grande maioria não estão preparadas para administrar suas 
finanças. Por se tratar de um tema consideravelmente novo, ainda há pouca mobilização em relação a discussões e práticas que despertem a curiosidade e conscientizem sobre a importância de ser um indivíduo bem resolvido financeiramente.

Segundo D'Aquino (2008), este atraso pode ser explicado pelo fato de que o país passou por oito mudanças de moeda em $52 \operatorname{anos}^{1}$ (1942 e 1994), sendo que, do total, seis aconteceram num intervalo de vinte anos. Lembra ainda, que está instabilidade fez que qualquer tentativa de planejamento financeiro tivesse resultados desanimadores.

Porém, o cenário está mudando, o tema tem recebido grande destaque nos últimos anos, pois passou a ser visto como um fator fundamental para garantir uma boa qualidade de vida. Exemplo disso, é a inserção da Educação Financeira como tema obrigatório nas escolas a partir de dezembro de 2019. Com a implementação da Base Nacional Comum Curricular, todas as instituições devem estar adaptadas as novas diretrizes, uma delas diz respeito à resolução de problemas dentro do contexto da Educação Financeira.

Segundo a BNCC, no ensino agora podem ser discutidos assuntos como taxas de juros, inflação, aplicações financeiras (rentabilidade e liquidez de um investimento) e impostos. Além disso, a Base também diz que essa abordagem favorece um estudo interdisciplinar envolvendo as dimensões culturais, sociais, políticas e psicológicas, além da econômica, sobre as questões do consumo, trabalho e dinheiro.

Já é possível identificar instituições dedicadas ao tema, como a DSOP Educação Financeira. Sua principal função é a disseminação da educação financeira no Brasil e no mundo, através da metodologia DSOP, criada pelo Phd Reinaldo Domingos. Para alcançar as pessoas, empresas e instituições de ensino, a organização oferece uma série de produtos e serviços, entre eles livros de educação financeira para crianças e adolescentes, sendo que uma de suas coleções, "O Menino do Dinheiro", fará parte da metodologia deste projeto.

Há também a Estratégia Nacional de Educação Financeira (ENEF), criada através do Decreto Federal 7.397/2010, com o objetivo de contribuir para o fortalecimento da cidadania ao fornecer e apoiar ações que ajudem a população a tomar decisões financeiras autônomas e conscientes. Foi criada através da articulação de nove órgãos e quatro organizações da sociedade civil, que juntos integram o Comitê Nacional de Educação Financeira (CONEF). Em seu site, Vida e Dinheiro, está disponibilizado diversos materiais gratuitos que abordam o tema, como: livros didáticos para ensino fundamental e ensino médio, artigos, vídeos e jogos.

\subsection{A importância de educar financeiramente as crianças}

Enquanto adultas, as pessoas desejam ter uma vida financeira equilibrada, permitindo que alcancem seus objetivos. Para isso, é de extrema relevância que a população seja educada financeiramente desde sua infância. Quando se fala em educar as crianças em relação ao dinheiro, quer-se basicamente formar indivíduos com capacidade para que futuramente tenham uma relação saudável com o dinheiro.

Como cita Cerbasi (2011), as crianças são influenciadas pelo comportamento de adultos ou de um grupo de pessoas que estejam a sua volta, aprendendo facilmente a conviver com regras. Porém é necessário que estas

\footnotetext{
1 Cruzeiro (1942-1965); Cruzeiro Novo (1965-1970); Cruzeiro (1970-1986); Cruzado (1986-1989); Cruzado Novo (1989-1990); Cruzeiro (19901993); Cruzado Real (1993-1994); Real (1º de julho de 1994) D’Aquino (2008, pg 8)
} 
sirvam para todos, devendo os mais experientes proporcionarem bons exemplos para aqueles que estão formando sua personalidade.

Inseridos em uma sociedade capitalista, os cidadãos estão cada vez mais reféns do consumismo exagerado. Os adultos com sede de novas conquistas, acabam iludindo-se com financiamentos e formas de pagamento facilitadas, onde em sua grande maioria estão embutidos altas taxas de juros.

\begin{abstract}
Um dos fatores que pode desestabilizar qualquer orçamento e impedir as pessoas de poupar é a compra iludida pela impressão do preço pequeno. A maioria das pessoas, levada por essa distorção, acaba comprometendo o orçamento, sobretudo ao fazer várias compras parceladas ao mesmo tempo. (DOMINGOS, 2012, p. 73).
\end{abstract}

Para o público infantil não é diferente, os pequenos estão em frente à televisão assistindo seus desenhos animados favoritos e a todo momento são bombardeados por comerciais de brinquedos, roupas e produtos de seu personagem favorito. Como grande maioria de pais, mães ou responsáveis trabalham fora, buscam suprir a ausência reunindo-se nos finais de semana em locais que atraem as crianças, mesmo que divertidas, estas ações podem estimular o consumismo infantil, como lembra D'Aquino (2008, p. 7):

[...] As compras no shopping, o almoço no restaurante, o DVD escolhido na locadora são programas familiares corriqueiros. Essa prematura exposição ao consumo tem levado algumas crianças, desde muito novas, a juntar e confundir o prazer da convivência com os pais ao prazer do consumo.

Esta é a realidade de muitas famílias brasileiras onde levar a criança para brincar em um parque, por exemplo, não é tão motivador quanto passear em lojas. É papel do adulto orientar a garotada que correr, pular, pedalar e brincar até não aguentar o cansaço além de ser mais relaxante é incrivelmente mais saudável. A falta dessas atividades torna as crianças tristes, desanimadas e adultas antes do tempo.

É na infância que os indivíduos precisam receber as devidas orientações para formar um bom comportamento financeiro. Apesar que após certa idade passam a conviver com um grupo maior de pessoas, como amigos, colegas e professores, é dever dos pais iniciar esta conversa com os filhos, mesmo que de forma lúdica. Adultos bem-preparados não sofrerão consequências negativas diante suas escolhas. Para D'Aquino (2008, p. 18), educar não é tarefa fácil,

[...] sobretudo quando se trata de educar num cenário em que a ética do consumo, as rápidas transformações dos vínculos familiares e a novidade de viver num ambiente de economia estável se juntam para nos confundir. Todavia, mesmo difícil, cansativa e tantas vezes desnorteadora, a aventura de proteger, formar e emancipar alguém a quem se que tão bem não tem paralelo em prazer e amor. Ensinar os filhos a lidar com dinheiro é parte fundamental nesse processo.

\title{
2.4 Aprenda a falar sobre dinheiro
}

[...] os pais quase sempre preferem preservar os filhos dessas preocupações até uma certa idade. Mas com isso acabam impedindo o início de um aprendizado importante. Afinal, se a casa é o ambiente onde aprendemos boa parte do que precisamos para a vida adulta, não seria nada mal aprender também a lidar com o dinheiro, a administrar receitas ${ }^{2}$ e despesas $^{3}$. (DOMINGOS, 2012, p. 12)

\footnotetext{
2 Receita é o conjunto de rendimentos. Isto é, o dinheiro que entra (seja de salário, mesada etc.).

3 Despesa é o conjunto de gastos. Isto é, o dinheiro que sai (lanche, balada, revistas etc.).
} 
Apesar do receio dos pais em falar sobre dinheiro com seus filhos, estudos apontam que já é possível iniciar aos quatro meses de vida, adiando alguns de seus desejos e ensinando-lhe a esperar alguns minutos. Para D'Aquino (2008), o bebê não pode compreender as palavras ditas, mas acolhido nos braços do cuidador e ouvindo a sua voz, aceitará melhor adiar a sua vontade. Diferente de deixá-lo no berço a chorar para aprender a esperar o desejo de agora. Para que se ensine de forma saudável para a criança é necessário que esta relação seja de segurança e não frustre nenhuma das partes envolvidas.

Levar o bebê a se acostumar a esperar para conseguir o que deseja, é uma arte que muitos adeptos do cheque especial e cartão de crédito não conseguem exercitar na vida adulta. Mas o mais importante é fazer com que os pais saibam lidar com a espera dos filhos, pois em vários casos a frustração dos adultos em não poder dar o presente desejado é superior ao sofrimento da criança.

\begin{abstract}
0 processo de habituar-se a tolerar as inevitáveis frustrações que vão surgindo no caminho dos filhos é vital não apenas para driblar as armadilhas cotidianas do consumo infantilninguém tem tudo o que quer-, mas, principalmente, para fundamentar a criação de adultos capazes de conviver com os limites da vida em sociedade, já que ninguém pode fazer tudo o que bem quer. (D'AQUINO, 2008, p. 19).
\end{abstract}

Segundo Cerbasi (2011), a mente de uma criança se desenvolve de maneira complexa, absorvendo diariamente milhões de estímulos externos. Os mais eficientes comporão, no futuro, referências e lembranças de medos, motivações, traumas e ensinamentos que formarão o raciocínio adulto em seus aspectos racionais e emocionais. Assim, uma educação financeira que integra conhecimento, habilidades e atitudes, estimulará os pequenos a tornarem-se adultos com uma vida equilibrada em todos os sentidos, emocional, pessoal, profissional e financeiro.

D’Aquino (2008) revela que as crianças estreiam no mundo do consumo quando pela primeira vez pedem para seus pais comprarem algo. Mesmo que com pouca idade, é possível notar que os mini consumidores dedicaram um bom tempo a observar o comportamento das pessoas com quem convive, percebendo assim que existe o dinheiro, que os adultos o possuem e que com ele podem comprar coisas divertidas, coloridas e gostosas. Sem hesitar os pais orgulhosos irão presentear a criança com aquilo que deseja, porém é necessário dobrar a atenção, pois com este pedido é necessário que inicie também a educação financeira.

Dessa forma, é importante que os responsáveis pelos pequenos saibam expor de forma clara a procedência do valor que a família gasta quando compra doces e brinquedos que desejam, uma vez que as crianças são seres absurdamente concretos e que entendem tudo ao pé da letra. Se simplesmente disser que o papai ou a mamãe está saindo para ganhar dinheiro, a criança terá a visão que dinheiro é algo fácil de conquistar, assim, os pais devem esclarecer que para ganharem dinheiro é fundamental que eles trabalhem, pois receberão um salário que será responsável por cobrir com as despesas da família como afirma D’Aquino (2008, p. 20):

O problema é que esse "ganhar" é compreendido pelas crianças na mesma dimensão dos presentes que eles ganham nos Aniversários ou no Natal. E como papai e mamãe "ganham" dinheiro, fica difícil entender que reajam aos pedidos insistentes de "Compra!" - sim, porque depois da primeira vez eles não param nunca mais de repetir isso-, sob o argumento de que "não têm dinheiro".

Para despertar na criança o interesse em aprender sobre o dinheiro, é importante demonstrar na prática a importância de cuidá-lo e utilizá-lo adequadamente. Para isso, é necessário mostrar a ela moedas e cédulas, chamando a atenção para a diferença de cores e tamanhos. 
Na vida, só aprendemos a respeitar aquilo que conhecemos. Com o dinheiro do país, não é diferente. Por isso, o primeiro passo para a educação financeira formal da crianças consiste em estimulá-la a reconhecer e manipular adequadamente as moedas, numa primeira fase, e, em seguida, as cédulas. (D'AQUINO, 2008, p. 21).

Finda a etapa de conhecer o dinheiro e o seu valor, é hora de levar a criança a estabelecimentos comerciais em que ela possa pesquisar o que é possível comprar com moedas de 50 centavos ou com cédulas de 2 reais, por exemplo. É essencial explicar que não se deve rasgar, molhar, riscar ou amassar as cédulas. Para D’Aquino (2008, p. 21):

\begin{abstract}
Este pode ser um excelente momento para presenteá-la com uma carteira que a ajude a manter guardada- e- cuidada- uma cédula de $\mathrm{R} \$ 1$. Além do estímulo a que a criança se aperceba, no concreto, a cuidar dinheiro, outras razões se alinham a favor desta etapa da educação financeira.
\end{abstract}

\title{
2.5 Incentivar as crianças a terem uma relação saudável com o dinheiro
}

\section{- Querer e precisar}

Para que tenha controle de suas finanças, um indivíduo deve saber selecionar onde deve aplicar o seu dinheiro. Quando isso for ensinado ainda na infância, facilitará a vida enquanto adulto, pois com auto controle é possível pensar antes de realizar uma compra, sabendo distinguir quando precisa realmente daquele objeto ou se é apenas um desejo do momento.

Com muitas propagandas ao seu alcance, a criança acaba querendo que os pais comprem brinquedos, jogos e roupas apenas por ver seu personagem favorito utilizando. Esta é a fase adequada para iniciar este assunto, mostrando aos pequenos que o que é necessário para algumas pessoas nem sempre é uma necessidade dele. Evita-se assim o acúmulo de objetos que não tem utilidade e também o desperdício do dinheiro.

Usando exemplos do cotidiano, procure explicar, na medida da compreensão da criança, que as pessoas têm diferentes necessidades e desejos porque moram em lugares diferentes, têm sexo ou idades diferentes ou são física e emocionalmente diferentes. (D'AQUINO, 2008, p. 23).

\section{- Mesada}

Para incentivar os filhos a lidarem adequadamente com o dinheiro, muitas famílias utilizam o método da mesada, que consiste em dar um valor previamente estimulado para que os pequenos administrem. Com este valor, eles poderão comprar brinquedos, lanches.

[...] como nos últimos anos vem crescendo o número de famílias que aderem à sua aplicação como maneira de educar os filhos para lidarem adequadamente com o dinheiro, é conveniente partirmos dessa intenção para delimitarmos as possibilidades e distorções que podem estar contidas nesta expectativa. Em primeiro lugar, a função primordial da mesada deve ser a de possibilitar que a criança seja igualmente capaz de ordenar um orçamento, definir escolhas para o dinheiro e desenvolver um plano de poupança. Em segundo lugar, a mesada é apenas uma dentre várias outras maneiras de se apresentar aos filhos o bê-á-bá das finanças. Tomada isoladamente, seu efeito é próximo de zero. (D'AQUINO, 2008, p. 52). 
É necessário que os pais ao adotarem este método, deixem claro ao filhos o objetivo desta prática. A mesada não deve servir como uma premiação para quando a criança conseguir uma nota satisfatória na escola nem como punição quando fizer algo que não for aprovado por sua família. 0 valor recebido deve ser uma forma de fazer com que as crianças criem responsabilidades em relação ao dinheiro, sendo necessário que consigam administrar a quantia dada durante o período estimulado, podendo este ser uma semana, conhecida como semanada e um mês, a mesada.

\section{MATERIAIS E MÉTODOS}

A etapa inicial consistiu na leitura de textos relativos a temática deste projeto, como artigos científicos, trabalhos acadêmicos, livros, teses e dissertações, entre outros. Assim, foi possível alcançar um bom número de autores, contemplando diversos posicionamentos sobre o assunto e encontrar materiais que serviram de apoio para o desenvolvimento deste trabalho, tornando mais enriquecedor.

A segunda etapa, compreendeu a aplicação de questionários com professores e alunos, para observar o que eles sabiam sobre educação financeira, qual sua relação com o dinheiro em seu dia a dia e como que os profissionais viam este tema e sua relevância para a educação básica. Foi aplicado um questionário com os docentes e outro com os estudantes.

Após, iniciou-se a contação de histórias da coleção "O Menino do Dinheiro". Através destes livros, buscouse abordar de forma lúdica algumas situações que envolvam dinheiro direcionadas ao público infantil. No dia em que foi lido o último livro, também foi confeccionado um cartaz, onde os alunos apontaram os principais ensinamentos durante o período de realização do trabalho.

Para a última etapa, havia sido planejado um "mercadinho", para o qual já tinha-se construído um painel. Nessa atividade, seriam simuladas situações de compra e venda de produtos, a fim de observar o comportamento dos alunos e a prática do que aprenderam durante os estudos sobre educação financeira. Porém, esta simulação não foi realizada, devido ao isolamento social decorrente da pandemia do COVID-19. Para substituir esta atividade e ser possível analisar a aprendizagem dos alunos, foi levado em consideração o cartaz que já haviam elaborado.

\section{RESULTADOS E DISCUSSÃO}

\subsection{Pesquisa realizada com as professoras}

Através do questionário, analisando as respostas obtidas, buscou-se entender como os professores veem a educação financeira e se consideram este tema pertinente aos alunos dos anos iniciais do ensino fundamental. Para isso, foram questionadas cinco professoras dos anos iniciais, através de 3 questões objetivas e 1 mista. As perguntas eram:

\section{Você sabe o que é educação financeira?}

Todos responderam que sim. 


\section{Você recebeu em algum momento da sua vida orientação de como lidar com o dinheiro?}

Todos responderam sim.

3. Você tem por hábito planejar os gastos mensais?

Todos responderam sim.

4. Como professor(a), você considera importante o tema educação financeira ser aplicado nos anos iniciais do ensino fundamental? Justifique.

Todos responderam sim, justificando pelo fato de a criança já ir tendo uma noção de como lidar com o dinheiro, aprender a economizar e planejar o futuro.

Após retornarem o questionário, houve uma conversa sobre este assunto, onde apostaram que eles possuem um básico conhecimento sobre a educação financeira, principalmente no que se refere a promoções, juros e impostos. Mas ressaltaram saber a necessidade deste tema para o desenvolvimento das crianças, porém lamentaram o fato de não haver uma preparação para que eles pudessem abordar o assunto em sala de aula.

\subsection{Pesquisa realizada com os alunos do $4^{\circ}$ e $5^{\circ}$ ano}

Esta pesquisa foi elaborada através de questionário para os alunos do $4^{\circ}$ e $5^{\circ}$ ano, turmas estas compostas de 20 alunos. Já havia um laço com os estudantes, uma vez que no ano anterior lecionei as disciplinas de Artes, Educação Física e Ensino Religioso para os mesmos, durante as horas atividades da professora titular. Assim, todos demonstraram empenho para contribuir com as atividades. No primeiro encontro, informei que eles estariam respondendo um questionário, contendo 3 perguntas dissertativas e 4 objetivas. As perguntas eram:

\section{Para você o que é dinheiro?}

Alguns alunos não souberam responder. Mas a maioria respondeu que é algo que utiliza-se para comprar tudo aquilo que é necessário; uma coisa muito boa. 
Gráfico 1- Para você o que é dinheiro?

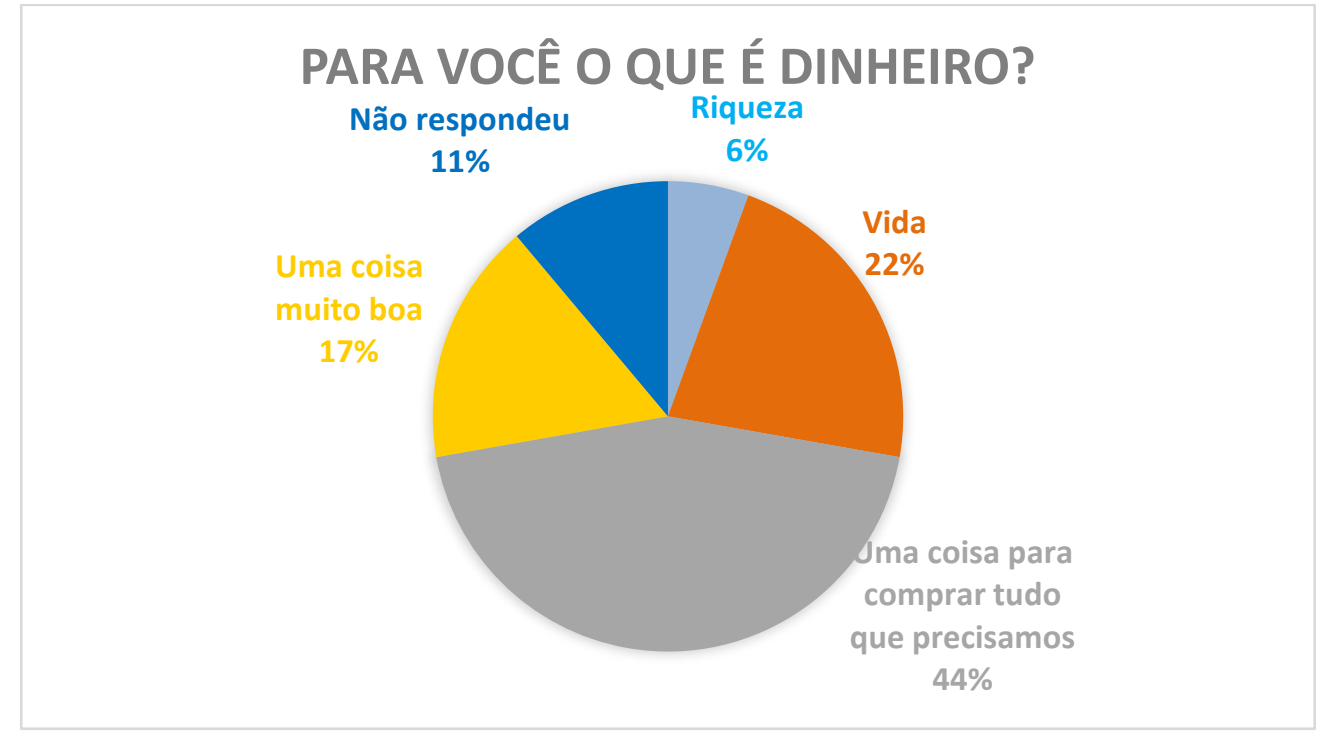

Fonte: autores

2. Quem da sua família lhe dá dinheiro?

Neste tópico, pode-se observar que pai e mãe são quem mais dão dinheiro aos filhos, seguidos de outros parentes próximos, como os avós.

Gráfico 2- Quem da sua família Ihe dá dinheiro?

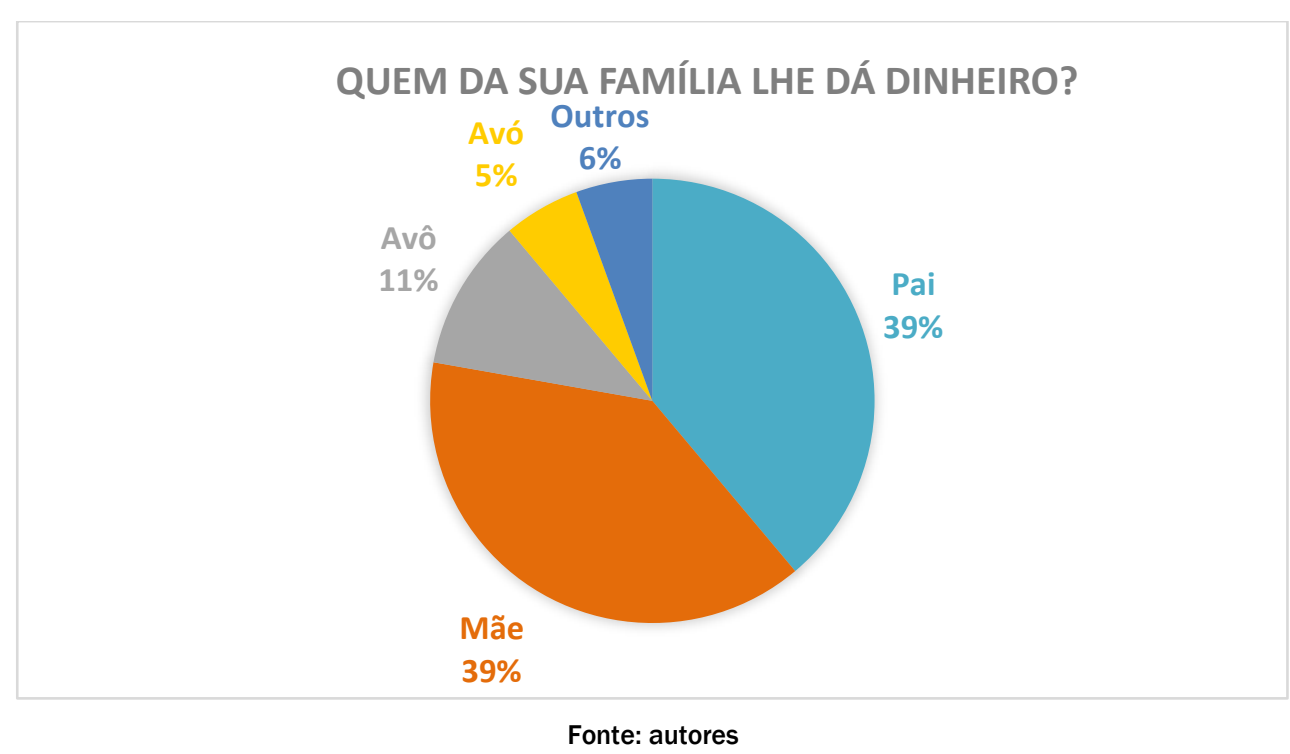

\section{O que você faz com o dinheiro que ganha?}

Metade dos alunos responderam que guardam, outros citaram comprar lanche e outras coisas que necessitam. 
Gráfico 3- 0 que você faz com o dinheiro que ganha?

\section{O QUE VOCÊ FAZ COM O DINHEIRO QUE GANHA?}

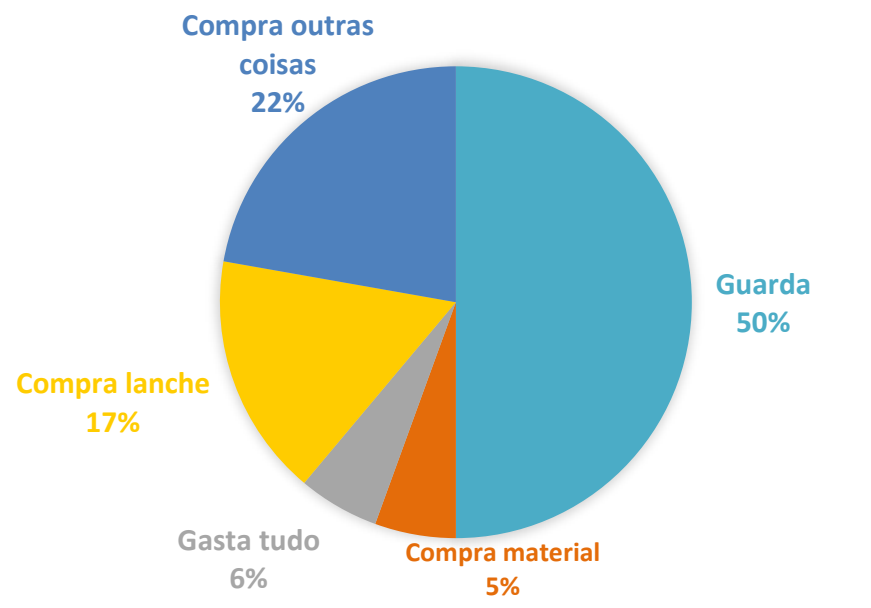

Fonte: autores

4. Você guarda um pouco do dinheiro que recebe? Se sim, como?

Todos os alunos responderam que sim, guardam um pouco do dinheiro que recebem. Citaram guardar em cofrinhos, no banco ou pedir para os pais guardarem.

Gráfico 4- Você guarda um pouco do dinheiro que recebe? Se sim, como?

\section{VOCÊ GUARDA UM POUCO DO DINHEIRO QUE RECEBE? SE SIM, COMO?}

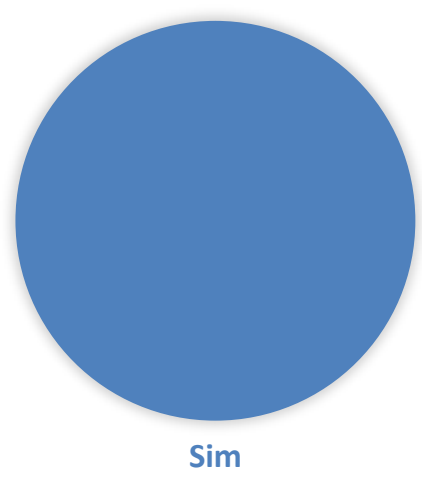

Fonte: autores

5. Você sabe usar o dinheiro para fazer compras e conferir o troco?

Grande maioria respondeu que sim, mas confessaram errar as vezes e levar bronca dos pais. 
Gráfico 5- Você sabe usar o dinheiro para fazer compras e conferir o troco?

\section{VOCÊ SABE USAR O DINHEIRO PARA FAZER COMPRAS E} CONFERIR O TROCO?

Não

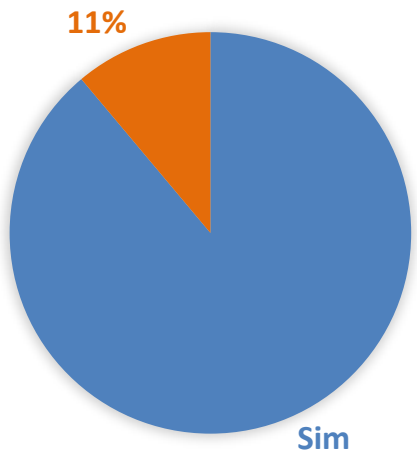

$89 \%$

Fonte: autores

6. Na escola você já aprendeu como usar o dinheiro?

Um número expressivo de estudantes respondeu sim, porém citaram que a maioria das vezes em forma de situações-problemas nos livros.

Gráfico 6- Na escola você já aprendeu como usar o dinheiro?

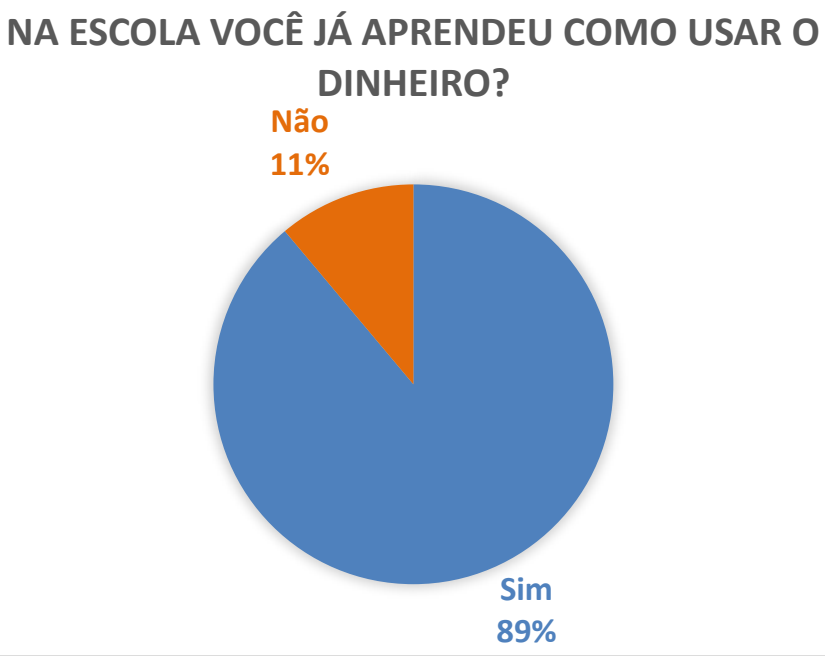

Fonte: autores

7. $\mathbf{O}$ que você deseja comprar com o dinheiro?

Nesta questão citaram diversos itens diferentes, mas os mais apontados foram brinquedos e moto. 
Gráfico 7- 0 que você deseja comprar com o dinheiro?

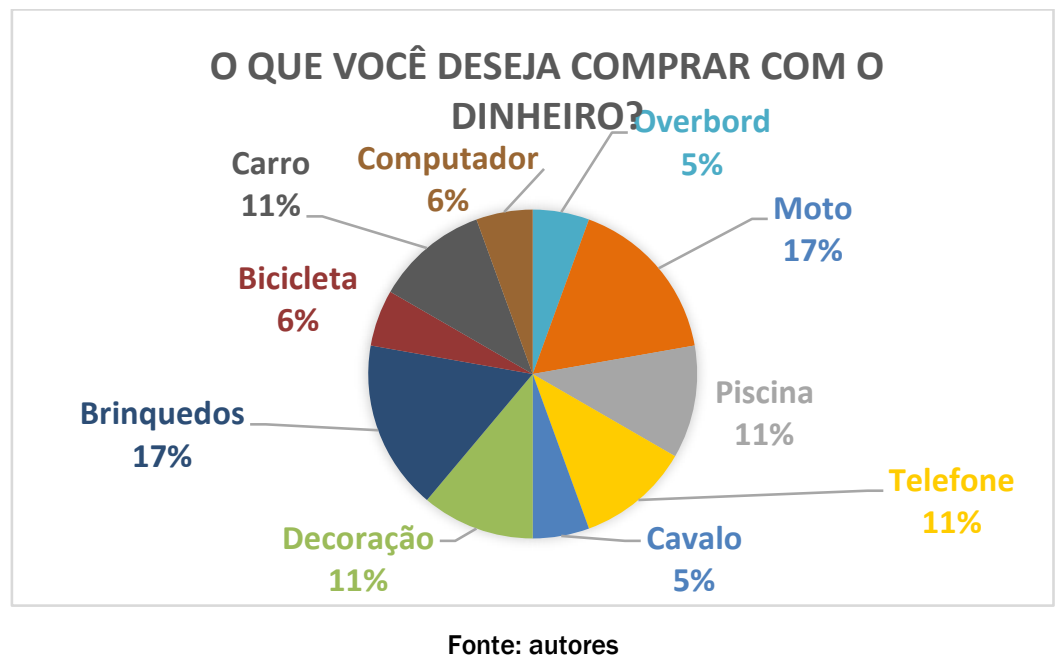

\subsection{Contação de Histórias}

Para conversar sobre o tema com os alunos de uma forma que fosse atrativa para eles, que envolvessem situações do dia a dia, foi escolhida uma coleção de livros chamada "O Menino do Dinheiro", do Reinaldo Domingos. Dessa forma, foram realizados encontros diários, para realizar a contação dessas histórias e discutir as situações que surgiam. Os alunos gostaram muito destas histórias, pois eram divertidas, chamavam a atenção e trabalhava a educação financeira de uma forma lúdica, que estimulava o interesse deles pelo tema, dando exemplos do seu cotidiano.

\subsection{Avaliação dos Alunos}

Foi prevista uma simulação de compra e venda pra que os alunos pudessem aplicar os conhecimentos adquiridos. Contudo, com o isolamento social devido a pandemia de Coronavírus, não foi possível realizar esta atividade. Para fim de avaliação do trabalho realizado, foi utilizado um cartaz onde os alunos indicaram o que aprenderam naquele período. Neste material, citaram os seguintes tópicos: economizar o dinheiro; utilizar o cofrinho; guardar dinheiro no banco; gastar apenas o necessário; aprender a esperar; ajudar as pessoas; não bater nos amigos; não roubar; não desistir dos sonhos; ser responsável; cuidar do meio ambiente; fazer novas amizades; ter criatividade; obedecer. É importante salientar que alguns tópicos como "não bater" ou "não roubar", que não estão diretamente ligados ao tema, também foram abordados nos livros, em situações que envolviam a educação financeira e outras situações que estão presentes no dia a dia.

\section{CONCLUSÃo}

Conforme mostrado neste trabalho, a educação financeira ainda vem engatinhando. Em contato com a realidade escolar, foi possível observar que muito ainda tem a ser feito. Trabalhar conceitos da educação financeira nesta pesquisa não só demonstrou que este estudo é necessário, como fez com que os alunos 
pensassem, praticassem o raciocínio rápido e fossem alertados para o consumo inconsciente e sem planejamento. Além disso, foi possível sensibilizar os estudantes para a importância de ter uma relação saudável, com o dinheiro, fazendo com que eles demonstrassem interesse pelo tema através das conversas no decorrer do trabalho. Portanto, pode-se considerar que a educação financeira é um tema indispensável, que deve ser trabalhado em casa e nas escolas, pois é fundamental para formar cidadãos responsáveis, organizados e conscientes.

\section{REFERÊNCIAS}

CERBASI, Gustavo. País inteligente enriquecem seus filhos: como educar seus filhos para se tornarem independentes e terem uma relação saudável com o dinheiro. Rio de Janeiro: Sextante, 2011

D’AQUINO, Cássia. Educação Financeira: Como educar seu filho. Rio de Janeiro: Elsevier, 2008.

DOMINGOS, Reinaldo. Ter dinheiro não tem segredo: Educação Financeira para jovens. São Paulo: DSOP Educação Financeira, 2012.

. O menino do dinheiro: sonhos de família. São Paulo: DSOP Educação Financeira, 2011.

. O menino do dinheiro: vai à escola. São Paulo: DSOP Educação Financeira, 2011.

. O menino do dinheiro: ação entre amigos. São Paulo: DSOP Educação Financeira, 2012.

. O menino do dinheiro: num mundo sustentável. São Paulo: DSOP Educação Financeira, 2013.

. O menino do dinheiro: pequeno cidadão. São Paulo: DSOP Educação Financeira, 2014.

. 0 menino do dinheiro: tempo de mudanças. São Paulo: DSOP Educação Financeira, 2015.

MARTINS, José Pio. Educação Financeira ao alcance de todos. São Paulo: Fundamento, 2004.

PRADO, Rosana de Souza. Educação Financeira no Ensino Fundamental I. 2013. 49 f. Monografia (Licenciatura em Pedagogia) - Universidade do Estado do Rio de Janeiro, Faculdade de Formação de Professores, São Gonçalo, 2013. Disponível em: < http://www.ffp.uerj.br/arquivos/dedu/monografias/rsp.pdf >. Acesso em: 20 ago. 2019. 